\title{
Erratum to: FDG-PET scans in patients with Kraepelinian and non-Kraepelinian schizophrenia
}

\author{
Marie-Cécile Bralet ${ }^{2,3,4} \cdot$ Monte S. Buchsbaum $^{1} \cdot$ Alex DeCastro $^{5}$ - Erin A. Hazlett ${ }^{6,7}$. \\ M. Mehmet Haznedar ${ }^{6,7} \cdot$ Lina Shihabuddin ${ }^{6} \cdot$ Serge A. Mitelman ${ }^{6,8}$
}

Published online: 30 November 2015

(C) Springer-Verlag Berlin Heidelberg 2015

\section{Erratum to: Eur Arch Psychiatry Clin Neurosci DOI 10.1007/s00406-015-0633-x}

Two co-authors Erin A. Hazlett and M. Mehmet Haznedar were inadvertently omitted from the author list of officially published article. The complete author group and their affiliation are given below.
Additionally, the below line was omitted in the acknowledgement section. Now, it is mentioned here.

The study was approved by James J. Peters Veterans' Administration Medical Center IRB.
The online version of the original article can be found under doi:10.1007/s00406-015-0633-x.

Monte S. Buchsbaum

monte.buchsbaum@gmail.com

Marie-Cécile Bralet

mcbralet@gmail.com

Alex DeCastro

alexdecastro2@gmail.com

Lina Shihabuddin

linashihabuddin@comcast.net

Serge A. Mitelman

serge.mitelman@mssm.edu

1 Departments of Psychiatry and Radiology, University of California, San Diego, 11388 Sorrento Valley Road, San Diego, CA, USA
2 Crisalid Unit (FJ5), CHI Clermont de l'Oise, 2 rue des finets, 60607 Clermont, France

3 Inserm Unit U669, Maison de Solenn, Universities Paris 5 11, 75014 Paris, France

4 GDR 3557 Recherche Psychiatrie, Paris, France

5 Department of Psychiatry, University of California, San Diego, 11388 Sorrento Valley Road, San Diego, CA, USA

6 Department of Psychiatry, Icahn School of Medicine at Mount Sinai, New York, NY 10029, USA

7 James J. Peters Veterans' Administration Medical Center, Bronx, NY, USA

8 Department of Psychiatry, Elmhurst Hospital Center, 7901 Broadway, Elmhurst, NY 11373, USA 